\title{
Cloning and Characterization of a Schistosoma mansoni cDNA Clone with a Specific Antigenic Expression during Development in a Vertebrate Host
}

\author{
Arlete Martins Coelho-Castelo, Vanderlei Rodrigues ${ }^{+}$
}

\begin{abstract}
Laboratório de Biologia Molecular de Parasitas, Departamento de Parasitologia, Microbiologia e Imunologia, Faculdade de Medicina de Ribeirão Preto, USP, Av. Bandeirantes 3900, 14049-900 Ribeirão Preto, SP, Brasil
\end{abstract}

Approximately $2.0 \times 10 \mathrm{cDNA}$ clones of an Schistosoma mansoni $\lambda$ gt11 cDNA library were screened in duplicate with serum from infected mice corresponding to distinct phases of infection. A cDNA clone (7/1) was isolated and recognized only by seven week serum. The clone was subcloned in $p G E X-2 T$ and Western-blot studies showed a specific antigenic expression confirming that only serum from the chronic phase is capable of recognizing this antigen. Dot-hybridization with RNA from different developmental phases of the parasite showed that the corresponding 7/1 RNA is expressed in all phases of parasite development in vertebrate hosts.

Key words: Schistosoma mansoni - antigen specific expression - cDNA - cloning

Schistosomiasis caused by Schistosoma mansoni is a chronic and debilitanting disease affecting 8 to 10 million people in Brazil (Lambertucci \& Barravieira 1994). Chemotherapy is currently the main tool in the control of this disease and the recent development of vaccines represents a new strategy in the control of transmission (Balloul et al. 1987, Goudot-Crozel et al. 1989, Shoemaker et al. 1992, Tendler et al. 1995). During development in vertebrate hosts the parasite follows a complex route of migration to reach the porta-hepatic system. This process is associated with important structural, physiological and biochemical adaptations with differential antigen expression. In vertebrate hosts, about $3 \mathrm{hr}$ after skin penetration cercariae transform into schistosomula which can be detected in the lungs during the first week of infection. Between the 4th and 5th week of infection the parasites of opposite sex become coupled and start oviposition in the porta-hepatic system (Miller \& Wilson 1978, Wilson \& Coulson 1986). The identification and characterization of phase-specific antigen expression may provide a better understanding of parasite biology and of the host-parasite interactions.

In the present study we have identified and

This work was supported by grants from FAPESP, CNPq and FINEP.

${ }^{+}$Corresponding author. Fax: + 55-16-633.6631. E-mail: vrodrigu@famrp.usp.br

Received 16 April 1997

Accepted 30 June 1997 characterized a cDNA clone with specific antigenic expression during $S$. mansoni development in a vertebrate host.

\section{MATERIALS AND METHODS}

Animal serum - Swiss mice were infected with 250 cercariae of $S$. mansoni LE strain by the method of Smithers and Terry (1965). Mouse serum samples were collected weekly for seven weeks after infection. Pooled serum from each week was purified by precipitation with $45 \%$ amonium sulfate, dialyzed against $10 \mathrm{mM}$ PBS, $\mathrm{pH} 7.4$, and used to immunoscreen a cDNA library.

Library screening - Duplicate filters of a recombinant $\lambda$ gt 11 cDNA library were immunoscreened with serum from the 1 st and $7 \mathrm{th}$; 2nd and 7 th; and 3rd and 7th weeks post-infection. Reactive clones were detected with goat anti-mouse $\operatorname{IgG}$ alkaline phosphatase conjugate at 1/5000 dilution and stored at $4^{\circ} \mathrm{C}$ in $\mathrm{SM}$ buffer $(20 \mathrm{mM}$ Tris- $\mathrm{HCl}$, $\mathrm{pH} 7.4,10 \mathrm{mM} \mathrm{MgSO} 4 ; 100 \mathrm{mM} \mathrm{NaCl}$ and $2 \%$ gelatin) containing $0.3 \%$ chloroform.

Dot-hybridization - $20 \mu \mathrm{g}$ of mRNA from different phases of the parasite life cycle were denatured and dot-blotted onto nylon membranes and covalently linked to the filter using UV exposure. The filters were hybridized with cDNA 7/1 labeled with biotin according to manufacturer instructions (Photogene).

Expression in Escherichia coli and partial purification of expressed protein - The insert 7/1 was excised with EcoRI, purified out of gels and ligated into the phosphatase treated EcoRI site of the expression vector pGEX-2T (Smith \& Johnson 1988). The recombinant plasmids were trans- 
formed into E. coli DH5 $\alpha$ (Hanahan 1983) and positive clones were grown in LB supplemented with $150 \mu \mathrm{g} / \mathrm{ml}$ ampicillin. Following induction with $1 \mathrm{mM}$ IPTG, the pelleted bacteria were resuspended in MTPBS $(15 \mathrm{mM} \mathrm{NaCl}, 160 \mathrm{mM}$ $\mathrm{Na} 2 \mathrm{HPO} 4,40 \mathrm{mM} \mathrm{NaH} 2 \mathrm{PO}$, and $0.5 \mathrm{mM}$ PMSF) and lysed by sonication. The bacterial lysate was made up to $1 \%(\mathrm{w} / \mathrm{v})$ in Triton X-100 and after centrifugation at $10,000 \mathrm{~g}$ the supernatant was incubated with $30 \mathrm{mg}$ glutathione-agarose beads for $30 \mathrm{~min}$ at room temperature. The glutathione-agarose beads were washed with PBS-Triton and incubated with thrombin at 25 units/ml according to the method of Smith and Johnson (1988). Beads were pelleted by centrifugation and the clarified supernatant was analyzed by SDS-PAGE under reducing conditions (Laemmli 1970)

Western blot analysis of recombinant antigen expression - For Western blot analysis, recombinant protein was electrophoresed as above and then transferred to nitrocellulose membranes. Blot was probed by overnight incubation with serum from different weeks post-infection and then incubated with goat anti-mouse IgG alkaline phosphatase conjugate and developed with nitroblue tetrazolium and 5-bromo-4-chloro-3-indolyl phosphate (Gibco).

\section{RESULTS}

Immunoscreening of the $\lambda$ gt11 S. mansoni library and analysis of clones - Approximately $2 \mathrm{x}$ $10^{5}$ plaques from the $\lambda$ gt11 library of $S$. mansoni were screened for expression of antigenic determinants with immune mouse antiserum against $S$. mansoni using duplicate filters. We isolated 1 recombinant clone (7/1) recognized by 7 th week serum but not by 1 st week serum, 5 clones ( $7 / 2$ a to e) recognized by 2 nd week serum but not by 7 th week serum, and 6 clones (7/6 a to f) recognized by 3 rd week serum but not by 7 th week serum. The cDNAs clones were isolated from recombinant phage and cut with the restriction enzyme EcoRI in order to determine the size of the insert fragments (Fig. 1).

The $7 / 1$ cDNA clone was subcloned on pGEX$2 \mathrm{~T}$ expression vector and the fusion protein recovered from bacterial lysate on glutathione-agarose beads (Fig. 2A). It was impossible to get the recombinant antigen without the GST portion after treatment with thrombin (Fig. 2B) probabily this impossibility may be explained due to conformation acquired by the complex (fusion protein) became the thrombin site inaccessible for the cleavage as described before in others situations (Guan \& Dixon 1991).

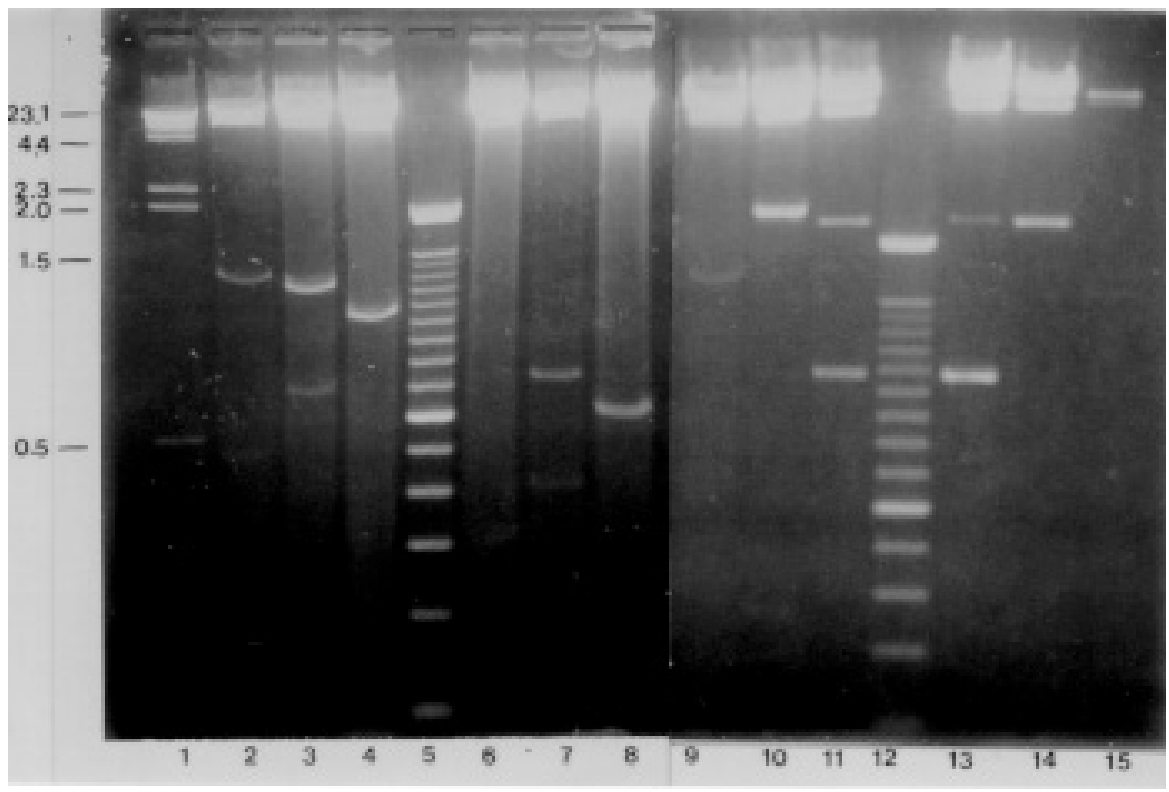

Fig. 1: characterization of Schistosoma mansoni cDNA clones. Recombinants clones of $\lambda \mathrm{gt} 11$ were digested with EcoRI for $2 \mathrm{hr}$ at $37^{\circ} \mathrm{C}$ and the size of inserts was visualized by electrophoresis on $1.5 \%$ agarose gel stained with ethidium bromide. Lane 1 : $\lambda$ DNA-Hind III. Lane 2: clone 7/1. Lane 3: clone 7/2a. Lane 4: clone 7/2b. Lane 5: $100 \mathrm{bp}$ DNA ladder. Lane 6: clone 7/2c. Lane 7: clone 7/2d. Lane 8: clone 7/2e. Lane 9: clone 7/3a. Lane 10: clone 7/3b. Lane 11: clone 7/3c. Lane 12: 100 bp DNA ladder. Lane 13: clone 7/3d. Lane 14: clone 7/3e. Lane 15: clone 7/3f. 


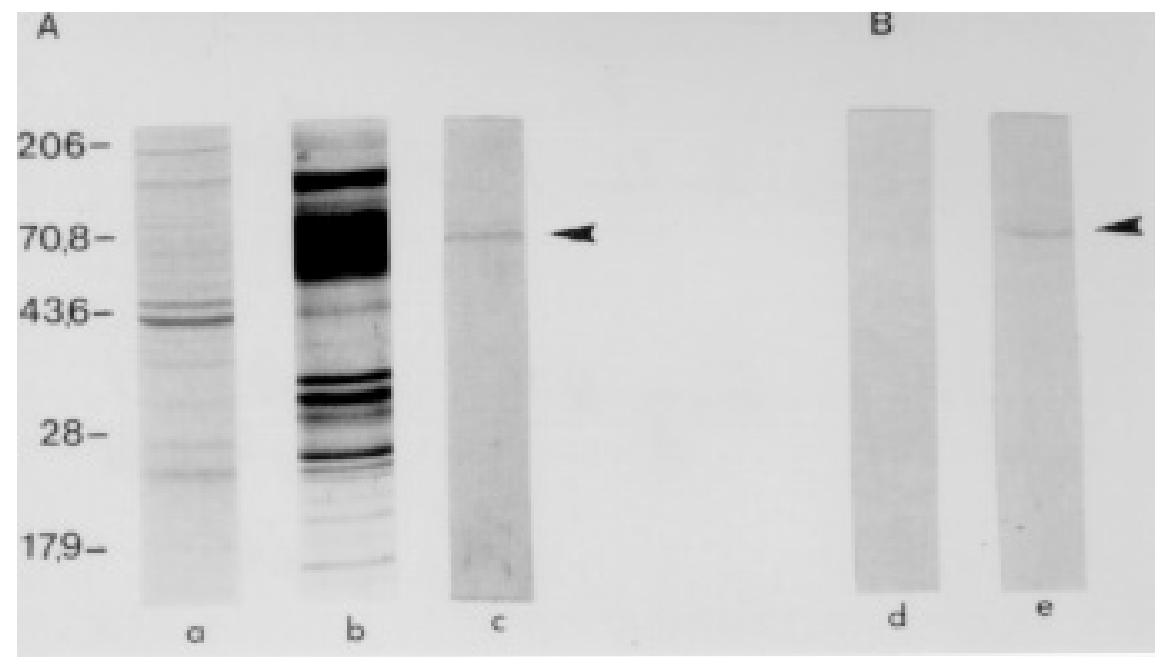

Fig. 2: SDS-PAGE of expression and purification of the pGEX 2T-7/1 recombinant clone. (A) Lysates of DH $5 \alpha$ transformed with pGEX 2T-7/1 without induction (lane a). After $60 \mathrm{~min}$ of induction (lane b). After purification with glutathione-agarose beads (lane c). (B). Supernatant of the incubation with glutathione-agarose beads and after thrombin cleavage (lane d). Material bound to glutathione-agarose beads (lane e). The position and sizes (kDa) of molecular weight markers are indicated.

Immunogenicity of the 7/1 clone during schistosome infection - It was of interest to determine whether clone $7 / 1$ showed specific expression during S. mansoni infection. Western blot of induced $7 / 1$ clone in pGEX-2T showed that the antigen produced as a fusion protein with GST reacted only with serum from mice with 6 and 7 weeks of infection (Fig. 3). GST alone was not recognized by either serum (results not shown).

Analysis of $m R N A$ expression related to $7 / 1$ $c D N A$ - In order to examine 7/1 mRNA expression, equal amounts of total RNA from miracidia,

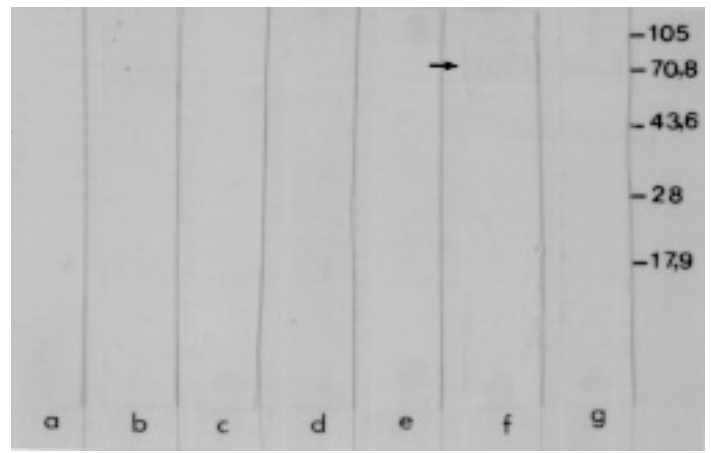

Fig. 3: Western blot analysis of the 7/1 fusion protein. Lysates of the induced pGEX 2T-7/1 clone were separated by SDSPAGE, Western blotted and probed with the following antisera. Lane a: 1 st week serum. Lane b: 2nd week serum. Lane c: 3rd week serum. Lane d: 4 th week serum. Lane e: 5 th week serum. Lane f: 6th week serum. Lane g: 7th week serum. Molecular weight markers $(\mathrm{kDa})$ are indicated on the right. cercariae, eggs, schistosomula, and male and female adult worms were blotted on nitrocellulose filters and hybridized to $7 / 1$ cDNA. The hybridization signal was detected with RNA from schistosomula and from male and female adult worms (Fig. 4A, tracks c, d, e, f) and was not detected with RNA from miracidia, cercariae or eggs (Fig. 4A, tracks a, b, g). As a control, the RNA samples were also hybridized with actin (Fig. 4B).

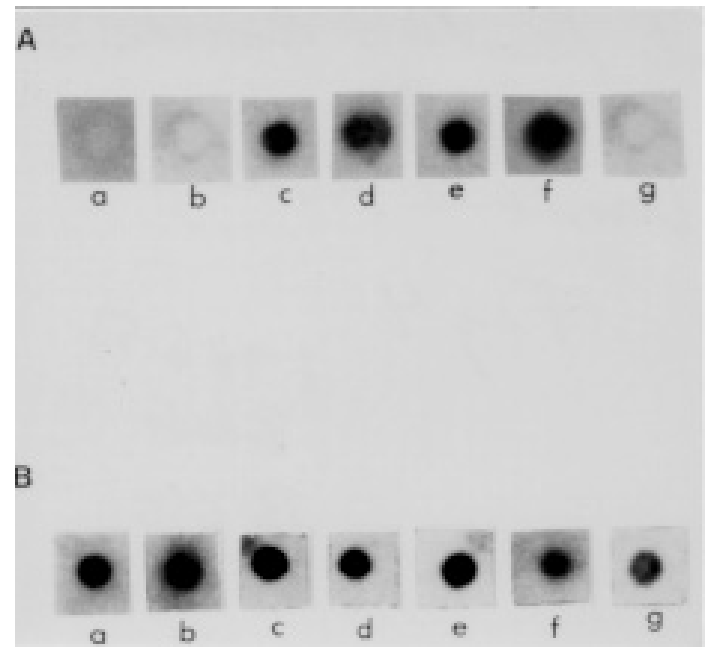

Fig. 4: Dot blot analysis of the mRNA 7/1 clone expression. Total RNA of the miracidia (lane a). Cercariae (lane b), schistosomula (lane c), male (lane d), female (lane e), worm pair (lane f). Eggs (lane g) were blotted and probed with the 7/ 1 cDNA clone. 


\section{DISCUSSION}

During the immunoscreening of an S. mansoni $\lambda$ gt11 cDNA library we isolated several clones with mouse immune serum from the 1 st to the 7 th week of infection. In this paper we have described a 7/1 clone reactive only with 7 th week serum, that encodes a fusion protein of $70-\mathrm{kDa}$. Since the molecular weight of GST is $26 \mathrm{kDa}$ the antigenic determinant is $44 \mathrm{kDa}$. Western blot analysis with mouse immune serum showed that the cDNA clone 7/1 expresses a polypeptide recognized by chronic mouse serum although the corresponding RNA is present in all phases of the parasite during its development in vertebrate hosts.

This antigen named $\mathrm{Sm} 44$ has a specific antigenic expression since only serum related to the chronic phase is able to recognize it although in terms of RNA expression the Sm44 antigen of $S$. mansoni is also present in other evolutionary phases of parasitism but is excluded by the immune system perhaps by some block due to host molecule incorporation or different distribution during the development of the parasite in vertebrate hosts, similar to other antigens described previously (Aronstein \& Strand 1983, Harn et al. 1985, Davies et al. 1986, Stein \& David 1986, Bobek et al. 1986, Grossman et al. 1990, Menrath et al. 1995).

Future studies to confirm this observation and the immunological role of the Sm44 antigen in the immune response to $S$. mansoni are planned.

\section{ACKNOWLEDGMENTS}

To Vania Fernandez and Olinda Mara Trevilatto for technical assistance.

\section{REFERENCES}

Aronstein WS, Strand M 1983. Lung-stage expression of a major schistosome surface antigen. $J$ Parasitol 69: 1027-1032.

Balloul JM, Sondermeyer P, Dryer D, Capron M, Grzych JM, Pierce RJ, Carvallo D, Lecocq JP, Capron A 1987. Molecular cloning of a protective antigen of schistosomes. Nature 326: 149-153.

Bobek L, Rekosh DM, Van Keulen H, Loverde PT 1986. Characterization of a female-specific cDNA derived from a developmentally regulated mRNA in the human fluke Schistosoma mansoni. Proc Natl Acad Sci USA 83: 5544-5548.

Davies AH, Blanton R, Rottman F, Maurer R, Mahmoud A 1986. Isolation of cDNA clones for differentially expressed genes of the human parasite Schistosoma mansoni. Proc Natl Acad Sci USA 83: 5534-5538.
Goudot-Crozel V, Caillol D, Djabali M, Dessein AJ 1989. The major parasite antigen associated with human resistance to schistosomiasis is a $34-\mathrm{kD}$ glyceraldehyde-3P-dehydrogenase. J Exp Med 170: 2065-2080.

Grossman Z, Ram D, Markovics A, Tarrab-Hazdai R, Lantner F, Ziv E, Schechter I 1990. Schistosoma mansoni: stage-specific expression of muscle-specific genes. Exp Parasitol 70: 62-71.

Guan K, Dixon JE 1991. Eukaryotic proteins expressed in Escherichia coli: An improved thrombin cleavage and purification procedure of fusion proteins with glutathione S-transferase. Anal Biochem 192: 262267.

Hanahan D 1983. Studies on transformation of Escherichia coli with plasmids. J Mol Biol 166: 557-580.

Harn DA, Mitsuyama M, Huguenel ED, David JR 1985. Schistosoma mansoni: detection by monoclonal antibody of a 22,000 dalton surface membrane antigen which may be blocked by host molecules on lung stage parasites. J Immunol 135: 2115-2120.

Laemmli UK 1970. Cleavage of structural proteins during the assembly of the head of bacteriophage T4. Nature 227: 660-685.

Lambertucci JR, Barravieira B 1994. Esquistossomose mansônica. Estudo clínico. J Bras Med 67: 59-100.

Menrath M, Michel A, Kunz WA 1995. Female-specific cDNA sequence of Schistosoma mansoni encoding a mucin-like protein that is expressed in the epithelial cells of the reproductive duct. Parasitology 111: 477-483.

Miller P, Wilson RA 1978. Migration of the schistosomula of Schistosoma mansoni from skin to lungs. Parasitology 77: 281-302.

Shoemaker C, Gross A, Gebremichael A, Harn D 1992. cDNA clone and functional expression of the Schistosoma mansoni protective antigen triose hosphate isomerase. Proc Natl Acad Sci USA 89: 1842-1846.

Smith D, Jonhson KS 1988. Single-step purification of polypeptides expressed in Escherichia coli as fusions with glutathione S-transferase. Gene 67: 31-40.

Smithers SR, Terry RJ 1965. The infection of laboratory hosts with cercariae of Schistosoma mansoni and the recovery of adult worms. Parasitology 55: 695-700.

Stein LD, David JR 1986. Cloning of a developmentally regulated tegument antigen of Schistosoma mansoni. Mol Biochem Parasitol 20: 253-264.

Tendler M, Vilar MM, Brito CA, Freire NMS, Katz N, Simpson AJG 1995. Vaccination against schistosomiasis and fascioliasis with the new recombinant antigen Sm14: potential basis of a multi-valent antihelminth vaccine? Mem Inst Oswaldo Cruz 90: 255256.

Wilson RA, Coulson PS 1986. Schsitosoma mansoni: dynamics of migration through the vascular system of the mouse. Parasitology 92: 83-100. 